\title{
Impact of various sterilization methods on growth and yield of oyster mushroom (Pleurotus florida)
}

\author{
MANOJ KUMAR KALITA \\ Department of Plant Pathology, B.N. College of Agriculture (A.A.U.), Biswanath Chariali, SONITPUR (ASSAM) \\ INDIA (Email : manojkvk@ymail.com)
}

\begin{abstract}
Oyster mushrooms (Pleurotus sp.) are one of the most appreciated mushrooms due to their high nutritional value, flavour, very good taste and medicinal value. It is grown in various lingo-cellulosic agro wastes thereby reduce the environmental pollution caused by its decomposition. In the process of mushroom cultivation, one of the most important aspects is the disinfection of the substrates. In the present study different substrate sterilization methods viz., hot water treatment for $30 \mathrm{~min}$, autoclaving at $15 \mathrm{lbs}$ pressure for 20 min, treatment with formaldehyde solution $(50 \mathrm{ml} /$ ltr.water), treatment with bavistin $(2 \mathrm{~g} / \mathrm{ltr}$. water) and treatment with ordinary water (control) were investigated. Paddy straw was used as the substrate for mushroom cultivation. In the investigation, it was found that substrates sterilized by autoclaving was the best as it took less time for spawn run (15.0 days), pin head formation (20.3 days), fruiting body formation (23.3 day) and produced the highest mushroom yield per bed $(892.35 \mathrm{~g})$ with biological efficiency of 89.24 per cent. Substrates sterilized with bavistin (890.25g/bed) and hot water $(886.23 \mathrm{~g} / \mathrm{bed})$ also produced good yield of mushroom which was comparable with those produced in autoclave sterilized substrate. Formaldehyde treatment behaved poorly as it took highest time for spawn run. As autoclaving of huge quantity of substrates in big farms is not convenient, chemical sterilization with bavistin can be practiced.
\end{abstract}

Key Words : Mushroom, Substrate, Sterilization, Yield

View Point Article : Kalita, Manoj Kumar (2015). Impact of various sterilization methods on growth and yield of oyster mushroom (Pleurotus florida). Internat. J. agric. Sci., 11 (1): 104-107.

Article History : Received : 09.07.2014; Revised : 17.11.2014; Accepted : 03.12.2014 